\title{
Mulheres e Desenvolvimento: o papel das mulheres no desenvolvimento do Território da Cidadania do J alapão - TO ${ }^{1}$
}

\author{
Women and Development: the role of women in development of \\ Citizenship Territories Program of Jalapão-TO \\ Mujeres y Desarrollo: el papel de las mujeres en eL desarrollo del \\ Territorio de la Ciudadanía del Jalapão-TO
}

\author{
Nayara Silva dos Santos \\ Universidade Federal do Tocantins, Brasil \\ nayara_kelly6@hotmail.com
}

\section{Helga Midori Iwamoto}

Universidade Federal do Tocantins, Brasil

helga.iwamoto@gmail.com

\section{Airton Cardoso Cançado}

Universidade Federal do Tocantins, Brasil

airtoncardoso@yahoo.com.br

\section{Gislane Ferreira Barbosa}

Universidade Federal do Tocantins, Brasil

gislane@ifto.edu.br

\section{Waldecy Rodrigues}

Universidade Federal do Tocantins, Brasil

waldecy@terra.com.br

\section{Resumo}

Este artigo teve como objetivo identificar o papel das mulheres no desenvolvimento do Território da Cidadania do Jalapão. A metodologia desenvolvida é de natureza qualitativa e dividiu-se em duas partes: a primeira buscou identificar o papel da mulher através da literatura existente; a segunda parte foi realizada através entrevista semiestruturada direcionada atores diversos de cada município que formam o Território. De forma geral, tanto a pesquisa bibliográfica como as entrevistas apontam que o papel das mulheres do Jalapão no curso dos últimos anos vem se redesenhando. Antes envolvidas com tarefas tipicamente domiciliares elas passam a desempenhar papel mais ativo na dinamização da economia.

Palavras-Chave: Mulheres Rurais; Jalapão; Desenvolvimento; Território da Cidadania.

\section{Abstract}

This article aimed to identify the role of women in the development of Citizenship Territories of Jalapão. The methodology is qualitative and divided into two parts: the first aimed at identifying the role of women through existing literature; the second part was performed through semi-structured interviews directed at various players in each county that make up the territory. Overall, both the literature and interviews show that the role of Jalapão women in the course of recent years has been 
redesigned. Before they were involved primarily with typical household tasks but now they have begun to play a more active role in boosting the economy.

Keywords: Rural Women; Jalapão; Development; Citizenship; Territory.

\section{Resumen}

Este artículo tuvo como objetivo identificar el papel de las mujeres en el desarrollo del Territorio de la Ciudadanía del Jalapão. La metodología es cualitativa y se dividió en dos partes: la primera buscó identificar el papel de la mujer a través de la literatura existente; la segunda parte se realizó a través de entrevista semiestructurada dirigida a diferentes actores de cada municipio que conforman el Territorio. En general, tanto la investigación bibliográfica como las entrevistas muestran que el papel de las mujeres del Jalapão en el curso de los últimos años se han rediseñando. Si antes se dedicaban a tareas típicamente domésticas, pasaron a desempeñar un papel más activo en la dinamización de la economía.

Palabras-Clave: Mujeres Rurales; Jalapão; Desarrollo; Territorio de la Ciudadanía.

\section{Introdução}

As mulheres rurais são agentes econômicos importantes, contribuem para a renda das famílias e para o desenvolvimento de suas comunidades de diversas formas. Essas mesmas mulheres sofrem, historicamente, com a desigual estrutura das relações sociais de gênero; a invisibilidade do seu papel na unidade produtiva como trabalhadoras e cidadãs reforçam seu lugar no espaço doméstico.

Embora haja avanços significativos no reconhecimento da contribuição do trabalho da mulher para o desenvolvimento, ainda existem muitos desafios a serem superados. A política adotada no Programa Territórios da Cidadania $^{2}$ (PTC) tem como um dos objetivos vencer a invisibilidade vivida pelas mulheres no meio rural.

Este trabalho busca visualizar e entender o papel da mulher no processo de desenvolvimento do Território da Cidadania do Jalapão - TCJ. O TCJ está localizado na região Norte, no sudeste do Estado do Tocantins e abrange uma área de 34.113,20
$\mathrm{Km}^{2}$, é composto por oito municípios.

Apesar dos poucos trabalhos encontrados focalizando essa temática, é possível dizer que o papel da mulher no território Jalapão, no curso dos últimos anos, vem se redesenhando. Antes envolvidas tipicamente com as tarefas domiciliares, como a organização do lar, educação dos filhos e com atividades rurais, passaram a desempenhar um papel mais ativo na dinamização da economia.

A literatura encontrada aponta que a 'metamorfose' que acontece no papel da mulher no Jalapão é impulsionada por dois eventos específicos: o desbravamento do parque do Jalapão como polo turístico de potencial nacional; e a utilização do capim dourado como matéria prima para a confecção de artesanatos destinados à comercialização.

É interessante assinalar que os trabalhos que abordam de forma mais próxima a temática 'mulher e desenvolvimento na região do Jalapão' são aqueles escritos por mulheres, como é caso, por exemplo, do artigo de Santos (2006) intitulado de 'A 
relação entre o desenvolvimento do turismo e a percepção ambiental das mulheres que vivem no entorno do Parque Estadual do Jalapão' e de Sousa e Parente (2012) que trabalham com o conceito de empoderamento das mulheres através da atividade artesanal do capim dourado na região do Jalapão.

A discussão aqui proposta busca, a partir do caso do Território do Jalapão, contribuir com a ampliação da visão sobre as mulheres rurais na sociedade brasileira e enriquecer a análise das relações de gênero com o reconhecimento de outras vozes no meio rural. O trabalho justifica-se, sobretudo, por fomentar o debate, que apesar de ter se mantido inerte por muito tempo, atualmente vem ganhando novas formas. $\mathrm{O}$ estudo permite, ainda, incentivar novas pesquisas para acompanhar a participação feminina no desenvolvimento regional.

Além desta introdução, o artigo traz um breve histórico do território do Jalapão, apresenta também uma sistematização dos estudos sobre mulheres. Em seguida, expõe a abordagem do desenvolvimento territorial e mulheres rurais e, em seguida, mostra o papel dessas mulheres no desenvolvimento do Território da Cidadania do Jalapão, evidenciado por meio da pesquisa bibliográfica. Por último, são feitas considerações finais.

\section{Território da Cidadania do Jalapão- To}

A região denominada Jalapão leva esse nome em função da existência de uma planta nativa chamada Jalapa. Essa região abrange uma área de $34.113,20 \mathrm{~km}^{2}$, foi configurada com Território da Cidadania do Jalapão em 2009, pelo Governo Federal, objetivando um novo modelo de desenvolvimento econômico por meio da redução das desigualdades sociais, com uma agenda de combate à pobreza extrema e recuperando a capacidade de planejar e investir.

O TCJ está localizado na região Norte do Brasil e é formado por oito municípios: Lagoa do Tocantins, Lizarda, Mateiros, Novo Acordo, Ponte Alta do Tocantins, Rio Sono, Santa Tereza do Tocantins e São Félix do Tocantins.

Figura 1: Território da cidadania do Jalapão.

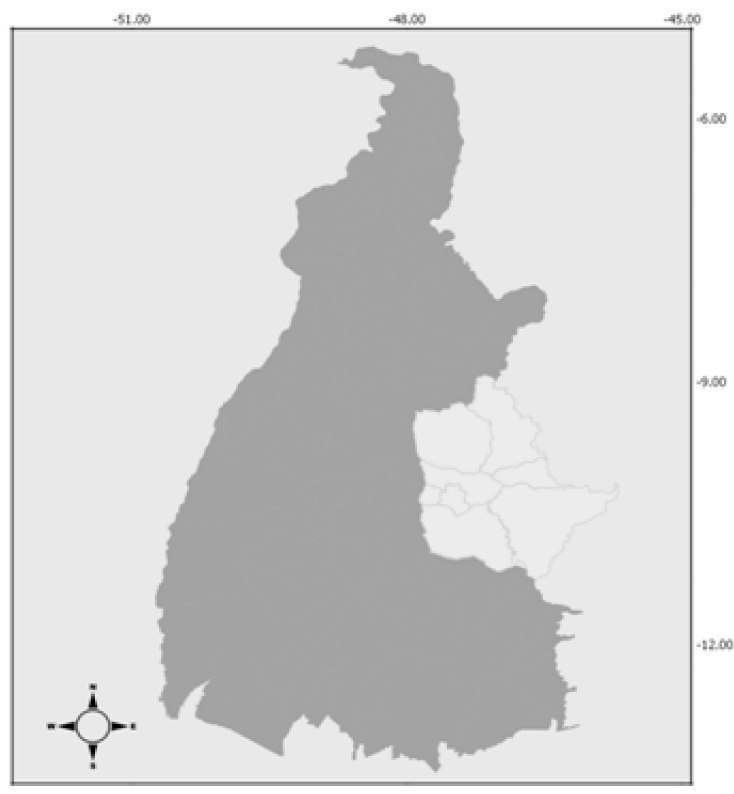

Fonte: Elaboraçào própria

Fonte: Elaboração própria

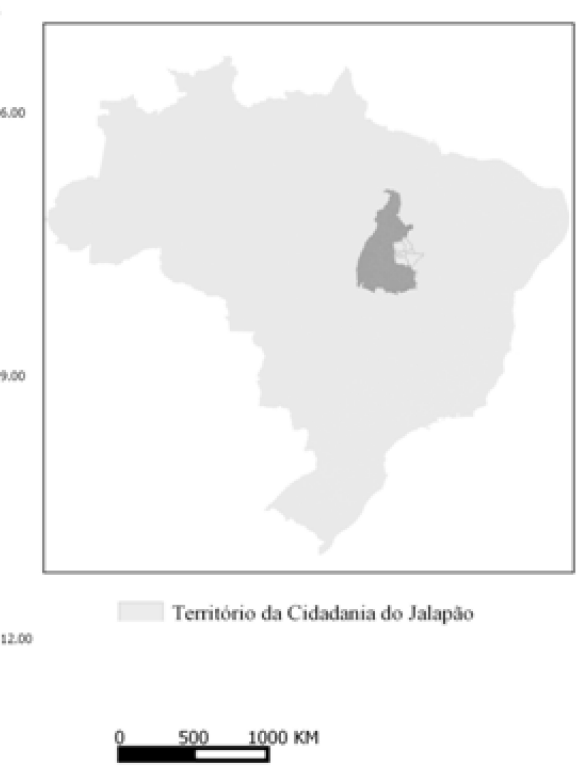

Nayara Silva dos Santos, Helga Midori Iwamoto, Airton Cardoso Cançado, Gislane Ferreira Barbosa e Waldecy Rodrigues 
Segundo o censo do IBGE (2010), o território tem população total 30.629 habitantes, destes, 53,27\% são homens e $46,73 \%$ são mulheres. $\mathrm{Da}$ população feminina, 65,52\% residem na área urbana e $37,63 \%$ na área rural. O município que possui o maior percentual de mulheres vivendo na área rural é Rio Sono, com $58,81 \%$.

O TJ apresenta um Índice de Desenvolvimento Humano Municipal $^{3}$ (IDHM) na faixa de 0,671 , que fica classificado como médio desenvolvimento e o índice $\mathrm{GINI}^{4}$ é de 0,42 , o que evidencia acentuadas desigualdades socioeconômicas.

Nessa região vivem, de acordo com o IBGE (2010), 30.629 habitantes dos quais 11.551 vivem na zona rural, o que corresponde a $37,69 \%$ do total. Na área rural tem cerca de 2.064 agricultores familiares e 184 famílias vivem em assentamentos, que constituem a demanda social do programa conforme o Sistema de Informações Territoriais (MDA, 2015).

\section{Os Estudos Sobre Mulheres}

Diversas autoras (p. ex. BEAUVOIR, 1949; ALVES; PITANGUY, 1985; JENAINATI; GROVES, 2007) apontam que a resistência de mulheres à opressão e dominação por outros segmentos da sociedade vem se realizando pelo menos desde os primeiros registros históricos. No entanto, apenas de aproximadamente 300 anos para cá é que se começaram a questionar as práticas de opressão/dominação das mulheres.

Uma das primeiras obras a questionar estas práticas foi escrita por Mill (1869), em que o autor, em conjunto com sua esposa e filha, argumenta no sentido de diversas bandeiras feministas. Podemos apontar algumas destas como a igualdade entre os sexos em termos morais e intelectuais, o sufrágio feminino (direito ao voto) e o reconhecimento da capacidade feminina em termos econômicos e de racionalidade.

$\mathrm{Na}$ mesma linha de raciocínio, Beauvoir (1949) discorre sobre vários aspectos que servem à subordinação feminina na sociedade, como a maternidade, o casamento e a educação diferenciada das meninas. Além disso, provê um histórico detalhado das formas de opressão feminina desde a préhistória.

Friedan (1963), por sua vez, aponta como aspectos da vida doméstica contribuem para a subordinação feminina. A autora argumenta contra os ideais americanos da época em que as mulheres só encontravam realização na maternidade e na vida doméstica.

Por meio deste breve histórico sobre o movimento feminista, pode-se depreender que os estudos de gênero são relevantes devido aos relatos e documentos históricos de experiências de resistência à opressão/submissão protagonizadas pelas mulheres. Estas experiências podem empoderar mais mulheres para novas iniciativas neste sentido.

Em termos conceituais, Scott (1986) aponta que o conceito gênero vem sendo utilizado pelas feministas como "uma maneira de se referir à organização social da relação entre os sexos" (p. 1053). Além disso, esta palavra serviria para rejeitar o "determinismo biológico implícito no uso de termos como 'sexo' ou 'diferença sexual'" (p. 1053).

Um exemplo dessa naturalização é o estudo etnográfico de Bourdieu (2010), sobre os berberes da Cabília, em que se documenta a visão androcêntrica naturalizada pelos indivíduos. O pesquisador defende que as sociedades ocidentais atuais conseguiram transpor esta visão de mundo por meio de novos sistemas educacionais e estruturas familiares. $\mathrm{O}$ autor argumenta, ainda, em favor de estudos que evidenciem os 
mecanismos operantes na família, religião, escola e Estado para a manutenção da subordinação feminina.

Discorrendo agora sobre as correntes existentes na área de gênero, é preciso ter ciência de que existem diversas maneiras propostas de categorizar os estudos de gênero. A própria Scott (1986) categoriza os estudos em marxianos, psicanalíticos e sobre patriarcado. No entanto, esta categorização falha em abarcar os estudos em países emergentes/em desenvolvimento e os estudos diferenciados em termos de minorias de raça/etnia e orientação sexual. Além disso, esta categorização não reconhece o feminismo liberal como o mainstream das correntes de gênero.

No sentido de sanar as deficiências das categorias de Scott (1986), Cálas e Smircich (1996) propõem categorizar os estudos de gênero como liberais, radicais, psicanalíticos, marxistas, socialistas, pós-modernos e póscoloniais. As autoras caracterizaram cada corrente feminista em termos de: raízes intelectuais, concepção da natureza humana, concepção de gênero, concepção de "boa sociedade", posições epistemológicas e metodologias mais utilizadas, conforme Quadro 1, a seguir:

Quadro 1 - Síntese das abordagens feministas

\begin{tabular}{|c|c|c|c|c|c|c|}
\hline $\begin{array}{l}\text { Escola de } \\
\text { pensamento }\end{array}$ & $\begin{array}{l}\text { Raízes } \\
\text { intelectuais }\end{array}$ & $\begin{array}{l}\text { Concepção } \\
\text { de natureza } \\
\text { humana }\end{array}$ & $\begin{array}{l}\text { Concepção } \\
\text { de sexo/ } \\
\text { gênero }\end{array}$ & $\begin{array}{l}\text { Concepção } \\
\text { de "boa } \\
\text { sociedade" }\end{array}$ & $\begin{array}{l}\text { Posições } \\
\text { epistemológic } \\
\text { as }\end{array}$ & $\begin{array}{l}\text { Metodologias } \\
\text { mais } \\
\text { utilizadas }\end{array}$ \\
\hline Liberal & $\begin{array}{l}\text { Teorias } \\
\text { políticas dos } \\
\text { sécs. XVIII e } \\
\text { XIX }\end{array}$ & $\begin{array}{l}\text { Indivíduos } \\
\text { são seres } \\
\text { autônomos e } \\
\text { racionais } \\
\text { (dualismo } \\
\text { mente/corpo } \\
\text { e } \\
\text { individualism } \\
\text { o abstrato) }\end{array}$ & $\begin{array}{l}\text { Sexo é parte } \\
\text { do organismo } \\
\text { biológico, } \\
\text { uma variável } \\
\text { binária. } \\
\text { Gênero é a } \\
\text { socialização } \\
\text { dos humanos } \\
\text { para o } \\
\text { comportamen } \\
\text { to apropriado } \\
\text { a cada sexo. }\end{array}$ & $\begin{array}{l}\text { Sociedade } \\
\text { justa que } \\
\text { permite aos } \\
\text { indivíduos o } \\
\text { exercício da } \\
\text { autonomia e } \\
\text { da auto- } \\
\text { realização } \\
\text { por meio de } \\
\text { um sistema } \\
\text { de direitos } \\
\text { humanos. }\end{array}$ & $\begin{array}{l}\text { Positivista, } \\
\text { Objetividade } \\
\text { e } \\
\text { neutralidade } \\
\text { em termos de } \\
\text { gênero }\end{array}$ & $\begin{array}{l}\text { Experimentos } \\
\text { de laboratório, } \\
\text { estudos } \\
\text { quantitativos. }\end{array}$ \\
\hline Radical & $\begin{array}{l}\text { Movimentos } \\
\text { de liberação } \\
\text { feminina da } \\
\text { década de } \\
1960 .\end{array}$ & $\begin{array}{l}\text { Seres } \\
\text { humanos são } \\
\text { fundamental } \\
\text { mente seres } \\
\text { sexuados. }\end{array}$ & $\begin{array}{l}\text { O sexo } \\
\text { feminino é } \\
\text { uma classe } \\
\text { oprimida. } \\
\text { O gênero é a } \\
\text { construção } \\
\text { social que } \\
\text { garante a } \\
\text { subordinação } \\
\text { da mulher ao } \\
\text { homem. }\end{array}$ & $\begin{array}{l}\text { Sociedade em } \\
\text { que } \\
\text { sexo/gênero } \\
\text { dos } \\
\text { indivíduos } \\
\text { não faça } \\
\text { diferença ou } \\
\text { matriarcado. }\end{array}$ & $\begin{array}{l}\text { Conheciment } \\
\text { o centrado no } \\
\text { feminino é } \\
\text { possível fora } \\
\text { das estruturas } \\
\text { patriarcais. }\end{array}$ & $\begin{array}{l}\text { Grupos de } \\
\text { conscientizaçã } \\
\text { o e estudos de } \\
\text { caso. }\end{array}$ \\
\hline
\end{tabular}


Mulheres e desenvolvimento: o papel das mulheres no

desenvolvimento do Território da Cidadania do J alapão - T0

\begin{tabular}{|c|c|c|c|c|c|c|}
\hline Psicanalítica & $\begin{array}{l}\text { Freud e seus } \\
\text { dissidentes } \\
\text { (Jung, Reich, } \\
\text { Fromm, entre } \\
\text { outros). }\end{array}$ & \begin{tabular}{|l|} 
A natureza \\
humana se \\
desenvolve \\
biologicamen \\
te e psico- \\
sexualmente.
\end{tabular} & $\begin{array}{l}\text { Os } \\
\text { indivíduos se } \\
\text { tornam } \\
\text { sexualmente } \\
\text { identificados } \\
\text { como parte } \\
\text { do seu } \\
\text { desenvolvim } \\
\text { ento psico- } \\
\text { sexual. } \\
\text { O gênero } \\
\text { estrutura um } \\
\text { sistema } \\
\text { social de } \\
\text { dominação } \\
\text { masculina } \\
\text { que } \\
\text { influencia o } \\
\text { desenvolvim } \\
\text { ento psico- } \\
\text { sexual. }\end{array}$ & $\begin{array}{l}\text { Não há } \\
\text { estruturação } \\
\text { social } \\
\text { diferenciada } \\
\text { por gênero, } \\
\text { pois ambos } \\
\text { os pais } \\
\text { compartilha } \\
\text { m } \\
\text { responsabilid } \\
\text { ades na } \\
\text { criação dos } \\
\text { filhos. }\end{array}$ & $\begin{array}{l}\text { As } \\
\text { abordagens } \\
\text { epistemológic } \\
\text { as propostas } \\
\text { por mulheres } \\
\text { são diferentes } \\
\text { das propostas } \\
\text { por homens, } \\
\text { devido às } \\
\text { condições } \\
\text { diferenciadas } \\
\text { no } \\
\text { desenvolvime } \\
\text { nto psico- } \\
\text { sexual. }\end{array}$ & $\begin{array}{l}\text { Estudos de } \\
\text { caso clínicos, } \\
\text { foco em } \\
\text { relações } \\
\text { sociais de } \\
\text { contextos } \\
\text { específicos; } \\
\text { histórias de } \\
\text { vida. }\end{array}$ \\
\hline Marxista & $\begin{array}{l}\text { "Correção" } \\
\text { da crítica } \\
\text { marxista ao } \\
\text { capitalismo } \\
\text { proposta no } \\
\text { séc. XIX }\end{array}$ & $\begin{array}{l}\text { A natureza } \\
\text { humana } \\
\text { reflete } \\
\text { condições } \\
\text { históricas e } \\
\text { materiais, } \\
\text { assim como } \\
\text { as relações } \\
\text { humanas. }\end{array}$ & $\begin{array}{l}\text { Gênero é } \\
\text { parte de } \\
\text { relações de } \\
\text { classe } \\
\text { historicizadas } \\
\text {, que } \\
\text { constituem } \\
\text { sistemas de } \\
\text { opressão } \\
\text { subordinados } \\
\text { ao } \\
\text { capitalismo. }\end{array}$ & $\begin{array}{l}\text { Sociedade } \\
\text { sem classes, } \\
\text { que permite o } \\
\text { desenvolvime } \\
\text { nto completo } \\
\text { da natureza } \\
\text { humana. }\end{array}$ & $\begin{array}{l}\text { O feminismo } \\
\text { deve adotar o } \\
\text { ponto de vista } \\
\text { de uma classe } \\
\text { oprimida pelo } \\
\text { capitalismo. }\end{array}$ & $\begin{array}{l}\text { Econometria, } \\
\text { análise } \\
\text { histórica e } \\
\text { dados macro- } \\
\text { sociais. }\end{array}$ \\
\hline Socialista & $\begin{array}{l}\text { Tentativa de } \\
\text { sintetizar as } \\
\text { correntes: } \\
\text { marxista, } \\
\text { psicanalítica } \\
\text { e radical } \\
\text { (Década de } \\
\text { 1970). }\end{array}$ & \begin{tabular}{|l|} 
Natureza \\
humana é \\
criada \\
historicament \\
e e \\
culturalmente \\
por meio de \\
relações \\
dialéticas \\
entre \\
biologia, \\
sociedade e \\
trabalho.
\end{tabular} & $\begin{array}{l}\text { O gênero é } \\
\text { socialmente } \\
\text { constituído } \\
\text { por meio de } \\
\text { interseções } \\
\text { de sexo, raça, } \\
\text { ideologia e } \\
\text { experiências } \\
\text { de opressão } \\
\text { dentro do } \\
\text { patriarcado e } \\
\text { do } \\
\text { capitalismo. }\end{array}$ & $\begin{array}{l}\text { Eliminação } \\
\text { de todos os } \\
\text { sistemas } \\
\text { públicos e } \\
\text { privados de } \\
\text { opressão } \\
\text { baseados no } \\
\text { sexo, gênero, } \\
\text { raça, classe, } \\
\text { etc. Relações } \\
\text { sociais } \\
\text { transformada } \\
\text { s. }\end{array}$ & $\begin{array}{l}\text { Pontos de } \\
\text { vista } \\
\text { feministas } \\
\text { representam } \\
\text { uma condição } \\
\text { histórica } \\
\text { particular de } \\
\text { opressão. São } \\
\text { mais } \\
\text { adequados } \\
\text { para } \\
\text { compreender } \\
\text { a sociedade } \\
\text { contemporân } \\
\text { ea. }\end{array}$ & $\begin{array}{l}\text { Estudos de } \\
\text { caso, } \\
\text { etnografias } \\
\text { institucionais, } \\
\text { etnometodolo } \\
\text { gia, foco em } \\
\text { como as } \\
\text { atividades do } \\
\text { micro-social } \\
\text { se conectam } \\
\text { aos processos } \\
\text { macro-sociais. }\end{array}$ \\
\hline
\end{tabular}

Nayara Silva dos Santos, Helga Midori Iwamoto, Airton Cardoso Cançado, Gislane Ferreira Barbosa e Waldecy Rodrigues 


\begin{tabular}{|c|c|c|c|c|c|c|}
\hline $\begin{array}{l}\text { Pós- } \\
\text { moderna }\end{array}$ & $\begin{array}{l}\text { Críticas } \\
\text { contemporân } \\
\text { eas francesas } \\
\text { às ideias de } \\
\text { "Conhecimen } \\
\text { to" e } \\
\text { "Identidade". }\end{array}$ & $\begin{array}{l}\text { Descentraliza } \\
\text { ção do sujeito } \\
\text { humanista } \\
\text { racional e } \\
\text { auto- } \\
\text { consciente.Su } \\
\text { bjetividade e } \\
\text { consciência } \\
\text { são efeitos } \\
\text { discursivos. }\end{array}$ & $\begin{array}{l}\text { Sexo/gênero } \\
\text { são práticas } \\
\text { discursivas } \\
\text { que } \\
\text { constituem } \\
\text { subjetividade } \\
\text { s específicas } \\
\text { por meio de } \\
\text { poder e } \\
\text { resistência na } \\
\text { materialidade } \\
\text { dos corpos } \\
\text { humanos. }\end{array}$ & $\begin{array}{l}\text { É necessário } \\
\text { desconstruir a } \\
\text { forma atual } \\
\text { de sociedade } \\
\text { por meio dos } \\
\text { discursos e } \\
\text { práticas que a } \\
\text { constituem }\end{array}$ & $\begin{array}{l}\text { Problematiza } \\
\text { cão da } \\
\text { própria idéia } \\
\text { de } \\
\text { epistemologia } \\
\text {, pois não há } \\
\text { um “sujeito } \\
\text { do } \\
\text { conhecimento } \\
\text { ”; no lugar } \\
\text { dele fica a } \\
\text { heterogeneida } \\
\text { de de } \\
\text { posições } \\
\text { subjetivas. }\end{array}$ & $\begin{array}{l}\text { Análise } \\
\text { textual, } \\
\text { desconstrução, } \\
\text { genealogias } \\
\text { foucaultianas. }\end{array}$ \\
\hline Pós-colonial & $\begin{array}{l}\text { Críticas de } \\
\text { minorias } \\
\text { feministas } \\
\text { ocidentais } \\
\text { subrepresenta } \\
\text { das ao } \\
\text { feminismo } \\
\text { ocidental. } \\
\text { Críticas de } \\
\text { teóricas de } \\
\text { outras partes } \\
\text { do mundo ao } \\
\text { feminismo } \\
\text { ocidental. }\end{array}$ & $\begin{array}{l}\text { Construto } \\
\text { ocidental que } \\
\text { emerge } \\
\text { tornando o } \\
\text { "Outro" } \\
\text { invisível ou } \\
\text { "quase } \\
\text { humano". }\end{array}$ & $\begin{array}{l}\text { Constituição } \\
\text { de } \\
\text { subjetividade } \\
\text { s complexas } \\
\text { além das } \\
\text { concepções } \\
\text { ocidentais de } \\
\text { sexo/gênero. } \\
\text { Foco nos } \\
\text { processos de } \\
\text { gênero } \\
\text { envolvidos } \\
\text { no processo } \\
\text { de } \\
\text { globalização. }\end{array}$ & $\begin{array}{l}\text { A “boa } \\
\text { sociedade” é } \\
\text { uma } \\
\text { ideologia } \\
\text { ocidental } \\
\text { produzida } \\
\text { por meio de } \\
\text { relações } \\
\text { coloniais que } \\
\text { favorecem a } \\
\text { ocidentalizaç } \\
\text { ão. Outras } \\
\text { formações } \\
\text { sociais são } \\
\text { possíveis. }\end{array}$ & $\begin{array}{l}\text { O } \\
\text { conhecimento } \\
\text { é um sistema } \\
\text { de relações } \\
\text { de poder } \\
\text { imposto pelo } \\
\text { Ocidente para } \\
\text { o resto do } \\
\text { mundo. } \\
\text { Outros } \\
\text { conhecimento } \\
\text { s/subjetividad } \\
\text { es são } \\
\text { possíveis. }\end{array}$ & $\begin{array}{l}\text { Análise } \\
\text { textual, } \\
\text { descontrução / } \\
\text { reconstrução } \\
\text { pós-colonial, } \\
\text { escritos de } \\
\text { testemunho de } \\
\text { experiências, } \\
\text { representações } \\
\text { híbridas. }\end{array}$ \\
\hline
\end{tabular}

Fonte: adaptado de Cálas e Smircich (1996, p.220-221, tradução nossa).

Pode-se, a partir do quadro anterior, caracterizar o presente estudo como póscolonial, pois este proporciona visibilidade às mulheres em contextos sociais e localidades fora do eixo convencional na área de gênero. Estudos tradicionais na área de gênero (linha liberal) costumam focar mulheres brancas, classe média/alta, com alta escolaridade, residentes em grandes centros.

Como forma de propiciar subsídios para a análise proposta neste artigo, serão apresentados os avanços acadêmicos nos estudos sobre mulheres rurais e artesãs, comumente invisibilizadas pelos estudos liberais de gênero.

\section{Desenvolvimento Territorial e Mulheres Rurais}

Conceitualmente, o desenvolvimento territorial é um processo de mudança estrutural empreendido por uma sociedade organizada territorialmente capaz de promover a dinamização socioeconômica e a melhoria da qualidade de vida de sua população (DALABRIDA, 2010). 
Segundo Ortega (2000), a grande motivação das diferentes experiências de desenvolvimento com foco locacional, desenvolvidas no Brasil, tem sido contribuir com o combate à pobreza e às desigualdades regionais, setoriais, sociais e econômicas, representando uma 'alternativa real' de geração de cidadania e de inserção competitiva dos territórios nos circuitos econômicos.

No Brasil, a partir da década de 1990, a abordagem territorial do desenvolvimento ganhou proeminência como estratégia de superar a insuficiência/ ineficácia das políticas públicas direcionadas ao interior brasileiro. Em 2008 foi lançado o Programa dos Territórios da Cidadania (PTC) como uma proposta de ações integradas entre a esfera federal, os estados e os municípios, com ampla participação social (BRASIL, 2009).

O grande desafio da ação territorial é criar condições para que seus beneficiários se insiram nas discussões sobre os rumos das políticas e dos processos de desenvolvimento. De forma geral, o programa tem como objetivo promover e acelerar a superação da pobreza e das desigualdades sociais, inclusive aquelas relacionadas a gênero, raça e etnia, que marcam o meio rural brasileiro.

Os Territórios da Cidadania podem, então, ser caracterizados como espaços socioterritoriais, que atuam com eixos estratégicos visando à organização e ao fortalecimento dos atores sociais, à adoção de princípios e práticas da gestão social e à promoção da implementação e integração de políticas públicas (ALLEBRANDT; DECKERT; SAUSEN, 2012).

Em termos de gênero, o programa busca superar as iniquidades reconhecendo o papel das mulheres trabalhadoras rurais para o desenvolvimento sustentável. As políticas de desenvolvidos direcionadas a esses questões buscam, além de superar a tradicional dicotomia entre 'mulher cuidadora' e 'homem provedor', ultrapassar a visão da mulher como uma 'força de trabalho secundária'.

Abramo (2010) diz que a inserção da mulher no trabalho é vista como um aspecto secundário do seu projeto de vida, da constituição de sua identidade e de suas possibilidades reais. Esta inserção ocorre apenas quando o homem, por definição o provedor principal, não pode cumprir esse papel por motivos diversos, como problemas de saúde e desemprego, ou quando se trata de uma família na qual a figura masculina não está presente e a mulher assume o papel de provedora por falta de alternativa.

Moser (1993) define os três tipos de papéis desempenhados pelas mulheres, women's triple role: o papel reprodutivo, papel produtivo e o papel de gerenciamento comunitário. Segundo a autora, o papel reprodutivo corresponde à reprodução biológica e às responsabilidades de ter e cuidar da educação dos filhos e dos trabalhos domésticos, requisitos básicos para garantia da manutenção e reprodução da força de trabalho. O papel produtivo corresponde ao trabalho realizado, tanto por mulheres como por homens, para a produção destinada ao consumo doméstico e as atividades agrícolas ou não agrícolas geradoras de rendimento. $\mathrm{E}$ o papel de gerenciamento comunitário corresponde às atividades em torno da oferta de itens de consumo coletivo, realizado na comunidade local, tanto urbana quanto rural.

Com essa leitura, a autora mostra a contribuição direta e indireta das mulheres para geração de riqueza. O problema é que esta contribuição não é contabilizada, pois parte da jornada cotidiana da mulher permanece oculta à sociedade e às próprias famílias rurais, devido ao processo histórico de hierarquização do trabalho dentro das famílias, advindas da divisão sexual do trabalho. Mesmo na invisibilidade, as 
mulheres estão ocupando terras plantando, colhendo e cultivando o desejo de ter uma terra livre e usufruí-la com seu trabalho (SALES, 2007).

Narcisor e Henriques (2008) dizem que o não reconhecimento do trabalho das mulheres rurais perpetua a sua marginalização, o que obstaculiza o desenvolvimento do seu potencial e da sua contribuição para o desenvolvimento em contexto geral.

Além do não reconhecimento do trabalho, as mulheres rurais são submetidas dentro do corpo familiar a um processo contínuo de dominação econômica e cultural, que as levam a ter, também, dificuldades para se expressar na vida pública, perpetuando um círculo vicioso de 'não direitos', de 'não cidadania' e de participação desigual no desenvolvimento (SILIPRANDI; CINTRÃO, 2011).

Apesar de todo esse cenário que vincula a figura das mulheres rurais a espaços domésticos ou que torna sua contribuição invisível, experiências desenvolvidas em todo o Brasil mostram que a participação das mulheres produtoras rurais em atividades de produção, comercialização, com pleno reconhecimento de seu papel, além de melhorar a sua renda e contribuir efetivamente para a dinamização das economias locais, ajuda a promover a sua autonomia econômica, aumenta sua sociabilidade, porque elas deixam de ficar presas somente ao espaço doméstico. Há ainda um aumento na sua autoestima, um maior reconhecimento junto às famílias e às comunidades, o aprendizado de novas tecnologias e a valorização da vivência de novas experiências (SILIPRANDI; CINTRÃO, 2011).

Desse modo, os esforços recentes giram em torno de multiplicar essas experiências, reconhecendo e gerando visibilidade ao trabalho da mulher rural. Para atingir esse fim, impulsionou-se a construção de políticas públicas para mulheres rurais, para a efetivação da cidadania e promoção da autonomia dessas mulheres trabalhadoras rurais. São ações que contemplam garantia dos direitos à cidadania, acesso a terra e aos recursos produtivos, acesso aos serviços rurais e ao comércio, resgate da memória coletiva e apoio a estudos feministas no campo, além do alargamento dos direitos das mulheres rurais no cenário internacional (HORA; BUTTO, 2014). É, então, uma estratégia integrada de acesso à cidadania e reconhecimento social das mulheres rurais.

\section{Metodologia}

O trabalho teve como objetivo identificar o papel das mulheres no desenvolvimento do Jalapão. A primeira etapa desenvolvida tratase de uma revisão da literatura, de caráter qualitativo, realizada a partir de levantamento bibliográfico nas bases eletrônicas de dados SciELO (Scientific Electronic Library On Line) e Google Acadêmico, no período 13 de março de 2015 a 21 de maio de 2015, com o emprego das seguintes expressões-chave: mulheres Jalapão, Jalapão desenvolvimento, mulheres rurais Jalapão, território da cidadania Jalapão.

A segunda etapa foi realizada por meio de entrevista semiestruturada, esse tipo de técnica é indicado para buscar informações sobre opinião, concepções, expectativas, percepções sobre objetos ou fatos ou ainda para complementar as informações sobre fatos ocorridos que não puderam ser observados pelo pesquisador, como acontecimentos históricos ou em pesquisa sobre história de vida, sempre lembrando que as informações coletadas são versões sobre fatos ou acontecimentos (MANZINI, 2004).

As entrevistas foram realizadas no dia 29 de junho de 2015, na sede do poder executivo do município de São Félix do Tocantins. A 
reunião foi marcada com o objetivo de discutir o projeto do PROINF $^{5} 2015$. Estavam presentes nesta reunião os prefeitos dos municípios de São Félix do Tocantins, Rio Sono e Lagoa do Tocantins e representantes dos municípios de Mateiros e Santa Tereza do Tocantins.

Além destes, a reunião contou com a presença dos representantes do colegiado territorial. Dos oito municípios que compõem o território da cidadania do Jalapão, somente os municípios de Lizarda e Novo Acordo não tiveram nenhum represente. É importante ressaltar que os colegiados territoriais são considerados espaços institucionalizados de participação e de legitimação da política pública, inserindo-se nos processos de gestão social dos recursos federais destinados ao desenvolvimento rural, são formados por representantes do poder publico e representantes da sociedade civil.

Cada município do Território da Cidadania do Jalapão tem quatro representantes no colegiado, dois do poder público (titular e suplente) e dois da sociedade civil (titular e suplente). A reunião, de forma geral, contou com a participação de 25 pessoas, foram entrevistados $56 \%$ dos presentes entre prefeitos (três prefeitos presentes), membros do colegiado (10 membros presentes, sendo três mulheres) e sociedade civil em geral, com representantes de todos os municípios presentes.

\section{O Papel das Mulheres no Desenvolvimento do Jalapão}

No levantamento bibliográfico nas bases eletrônicas de dados SciELO (Scientific Electronic Library On Line) e Google Acadêmico, na tentativa de identificar o papel das mulheres no desenvolvimento do Jalapão, através de publicações já realizadas, certificou-se que poucos são os trabalhos que de, alguma forma, tomam a mulher como sujeito ativo dessa cena e que abordam o papel mulher no desenvolvimento do Jalapão.

Os trabalhos encontrados, como o de Santos $(2006,2007)$ e Sousa e Parente (2012) permitem-nos dizer que o papel das mulheres do Jalapão, no curso dos últimos anos, vem se redesenhando. Antes, as mulheres da região se envolviam tipicamente com as tarefas domiciliares como a organização do lar, educação dos filhos e com atividades rurais. Atualmente, desempenham papel mais ativo na dinamização da economia.

A literatura aponta que esse movimento ocorre devido ao desbravamento do parque do Jalapão como polo turístico de potencial nacional e a utilização do capim dourado como matéria prima para a confecção de artesanatos destinados à comercialização.

No início da década de 1990, o Jalapão surge no cenário turístico como uma rota nacional do ecoturismo. $\mathrm{O}$ interesse turístico no território do Jalapão nasce devido ao conjunto excêntrico de belezas naturais e ao acervo cultural, presente de intenso culto às tradições sertanejas e a simplicidade dos hábitos ainda preservados na comunidade.

Apesar do conjunto de fatores naturais favoráveis ao turismo a estrutura de todo território ainda não é compatível com seu potencial. Deste modo, a exploração dessa atividade ainda depende de um esforço dos atores sociais locais onde as mulheres desempenham papel importante. As pousadas existentes são mantidas em grande maioria com a mão-de-obra familiar (BENVINDO, 2009). Algumas são de propriedade de mulheres fazendo com que as mesmas desempenhem atividades, desde a administração a tarefas bem típicas como cuidar da alimentação, da organização e limpeza dos ambientes.

A projeção turística do Jalapão difundiu o artesanato produzido a partir do capim dourado. Na bibliografia encontrada, as ações 
das mulheres relacionadas ao turismo ainda aparece de forma muito incidental. Já nas atividades com o capim dourado, elas são apresentadas como protagonistas da ação. Isso porque a atividade artesanal com o capim dourado sempre esteve vinculada à figura da mulher.

Guilhermina Rodrigues Matos, conhecida Dona Miúda ${ }^{6}$, é a grande matriarca da comunidade do Mumbuca, povoado da região do Jalapão, lugar de origem da técnica de tecer o capim. Dona miúda é considerada responsável pela disseminação do artesanato feito com capim dourado (MEDINA, 2012).

A arte de tecer o capim é herança passada pelos indígenas da etnia Xerente, em meados de 1930. A técnica foi aprendida por famílias do Povoado da Mumbuca, na região do Jalapão, quando um grupo de índios Xerentes acampou na região e, desde então, é passada de geração em geração nas comunidades jalapoeiras.

Apesar do nome, o capim dourado não é propriamente um capim e sim uma sempre-viva, planta da família das Eriocaláceas, cujo nome científico é Syngonanthus nitens. Os pequenos maços de hastes do capim dourado são costurados com uma fibra fina e resistente obtida de folhas novas da palmeira buriti (Mauritia flexuosa). Essas duas espécies ocorrem naturalmente no Cerrado do Brasil Central e são muito abundantes no Jalapão (CATALAGO, 2014, p.3).

A prática em si é anterior à abertura trazida pelo turismo, porém, a princípio, as artesãs restringiam a produção a utensílios domésticos, pois ainda não havia um núcleo produtor destinado à comercialização das peças, somente esporadicamente, eram comercializadas quando se tornaram moeda de troca dos moradores no comércio externo à comunidade.

Apenas na década de 1990, mediante um conjunto de ações governamentais que visaram dinamizar o Jalapão, e prioritariamente a área do Mumbuca, o produto começou a adquirir valor constituindo-se em uma importante fonte de renda para o povoado (MELLO, 2014).

Com o apoio governamental, as artesãs começaram a aperfeiçoar o modo de produção das peças e formaram associações. Entre 1999 e 2002, foram realizadas oficinas com a comunidade para aprimorar o artesanato em sua funcionalidade, o acabamento das peças e incentivar a criatividade de novos designs para a comercialização, sendo patrocinadas pelo SEBRAE e pela Secretaria de Cultura do Estado do Tocantins (BELAS, 2012).

$\mathrm{O}$ artesanato com o capim dourado constitui importante fonte de renda para muitas famílias, especialmente aquelas geridas por mulheres (NUNES, 2013). Pereira (2012) identifica o perfil das famílias encontradas na comunidade Mumbuca, principal povoado da região do Jalapão e conclui que $27 \%$ das unidades domésticas estão sob o comando exclusivo das mulheres e que $55 \%$ das mulheres partilham com os homens essa liderança.

Com a disseminação do artesanato do capim dourado, como alternativa de geração de renda, Santos (2007) diz que houve um processo de inversão de papéis homem/mulher na região do Jalapão, a qual autora chama de "revolução silenciosa". Segundo a autora, "a mulher passa de uma condição de 'cuidadora' da família, para a de provedora, uma vez que vem das suas mãos a maior fonte de recursos" (SANTOS, 2007, p. $52)$.

De alguma forma, esse é um processo semelhante ao que aconteceu na sociedade moderna em um contexto geral, no caso das 
mulheres do Jalapão ele pode ser considerado processo tardio. Santos (2007) diz que, em um primeiro momento, houve uma rejeição por parte dos homens, inclusive com alguns casos de violência contra a mulher, pois as mulheres deixavam de dedicar-se exclusivamente as atividades do lar e passavam usar parte do tempo para aprender e aperfeiçoar o artesanato.

De forma geral, as mudanças na vida das mulheres artesã/rurais são sempre bem assimiladas no núcleo familiar. Siliprandi e Cintrão (2011) explicam que isso acontece em função da perda do monopólio dos homens no gerenciamento da renda obtida, de alterações na divisão sexual do trabalho e de uma maior presença das mulheres na vida pública.

Desde então, as mulheres jalapoeiras passaram a se organizar e a buscar espaços legítimos para opinar e defender a própria atividade. A portaria que regulamenta a colheita, foi implementada através da atuação conjunta entre as associações de artesãs do capim dourado e a Naturatins ${ }^{7}$ (SANTOS, 2006). O documento prevê medidas que padronizam a coleta e manipulação do capim dourado, de modo que uma série de regras seja respeitada para manejo de forma a garantir a sustentabilidade do capim e consequentemente do artesanato da região.

Sousa e Parente (2012) enfatizam que a dinâmica em que as mulheres estão envolvidas na região do Jalapão levam a um processo de empoderamento, uma vez que se constrói uma nova perspectiva em relação ao econômico, social e pessoal. Segundo as autoras, a participação em associações, principalmente em cargos de presidente, tem provocado novas configurações sociais. A articulação entre as mulheres contribui tanto para o desenvolvimento da atividade, bem como para o seu próprio desenvolvimento levando assim ao empoderamento. De certo modo, é um processo de que combate as velhas práticas patriarcais e inibe reprodução das relações desiguais de gênero.

Atualmente, o artesanato de capimdourado é famoso em todo Brasil. A distribuição de tarefas na manufatura já conta com homens (adultos e jovens) para a colheita e confecção de algumas peças, mas as mulheres ainda se constituem como o maior quantitativo de pessoal na produção.

Cerca de 10 associações da região do Jalapão trabalham com artesanato de capimdourado. As peças produzidas são vendidas em feiras, lojas das capitais e até mesmo fora do Brasil. Segundo Sampaio (2010), a renda desses produtos é o principal sustento das famílias.

Toda a articulação que existe entorno do capim dourado, no Jalapão, não é característico apenas desse território, em todo o Brasil o artesanato tem sido usado como uma estratégia de fomento ao desenvolvimento humano, social e econômico, principalmente para mulheres das aéreas rurais.

As artesãs tornam-se importantes no contexto do desenvolvimento, não simplesmente por estar empregando uma técnica artesanal, mas porque estarem inseridas num contexto em que ser uma artesã possui um significado social em articulação com outros significados, dos quais ela compartilha (SAPIEZINSKAS, 2012).

O resultado das entrevistas, de certo modo, ratificam os resultados encontrados com a pesquisa bibliográfica, quando mostra nas falas dos entrevistados a evolução que houve no papel da mulher, a contribuição da mulher para o desenvolvimento de todo território, por meio de seu trabalho com o artesanato de capim dourado e do turismo. A participação da mulher nas arenas de discussão dos problemas sociais.

As perguntas direcionadas aos entrevistados buscaram identificar, entender a 
participação e a contribuição da mulher no desenvolvimento do Jalapão. Para isso, os entrevistados foram questionados sobre a importância do capim dourado para o território; quem são as principais pessoas que trabalham com o capim dourado; se historicamente houve mudança no papel da mulher em relação às atividades que desempenham; se as mulheres participam das decisões ou ações que envolvem questões do município/território; se as mulheres desempenham atividades agrícolas, se as mulheres desempenham atividades relacionadas ao turismo e a valorização da mulher no meio rural.

Os resultados da entrevista ultrapassaram os limites da pesquisa bibliográfica, mostrando outras realidades para além do turismo e do artesanato. Identificou-se, também, a participação efetiva das mulheres e sua contribuição para o desenvolvimento de todo o território.

Neste aspecto, foi elucidativo entender que nem todos os municípios do território tem o mesmo potencial para as atividades turísticas e para o artesanato do capim dourado. $\mathrm{O}$ artesanato de capim dourado está presente em todos os municípios do território, mas em dimensões diferentes. Mateiros, São Félix do Tocantins e Ponte Alta são aqueles que mais se destacam nesse meio de geração de renda. Da mesma forma, nem todos os municípios tem o mesmo o potencial para o turismo.

Nos municípios onde o artesanato e o turismo não oferecem muitas possibilidades a agricultura familiar, torna-se alternativa possível para geração de renda. O município de Rio Sono, por exemplo, tem $61,51 \%$ da população vivendo na área rural (é também o que possui o maior percentual de mulheres vivendo na área rural com 58,81\%), tem uma produção agrícola familiar expressiva e com intensa participação das mulheres.

Nas três atividades centrais da região (capim dourado, turismo e agricultura familiar), as mulheres desempenham papel importante, elas cultivam desde hortas e frutas no quintal de casa, até plantações maiores de mandioca para alimentar as casas de farinhas, feijão, entre outros. Muitas dessas mulheres rurais são as responsáveis pelo sustento da família.

O processo iniciado no Jalapão apresenta características de um processo de desenvolvimento local/territorial, no qual se busca, através dos atores locais, mobilizar e explorar as potencialidades locais, com o objetivo de contribuir para elevar às oportunidades sociais procurando preservar a identidade e cultura de um povo.

No conjunto, as produções teóricas existentes compreendem mulheres da região do Jalapão como sujeitos de transformação de sua realidade, a postura coletiva como uma forma de auto-organização para enfrentar obstáculos e potencializar as oportunidades.

Toda a proeminência turística, alcançada na região do Jalapão, associada ao reconhecimento do artesanato de capim dourado nos últimos anos, contribuiu para melhora dos indicadores sociais da mesma. Santos et al. (2008), por exemplo, calcularam o índice de qualidade de vida humana $\left(\mathrm{IQV}^{8}\right)$ no período de 2000 a 2008 da comunidade de Mumbuca, e concluíram que esta aumentou expressivamente, de 0,1833 para 0,390. O item com maior crescimento na composição do IQV foi o emprego e renda, que cresceu cerca de $1.321,96 \%$.

Os esforços dos atores sociais da região, nesse processo, resultaram em melhoria para além do econômico. A região iniciou um processo de estruturação socioeconômica, apresentando melhoras significativas nos indicadores sociais como educação, saúde, moradia, emprego e renda.

Analisando os resultados do Índice Firjan de desenvolvimento municipal dos 
municípios que pertencem ao território da cidadania do Jalapão, é possível verificar os resultados alcançados no ano de 2005 (primeiro ano em que o índice foi calculado) e no ano de 2011 (última versão). indicadores individuais, na vertente educação, o município de Lagoa do Tocantins apresentou um crescimento de mais de $100 \%$. Já no indicador Saúde, o município que ganha destaque é Novo Acordo que teve o

Quadro 2: Evolução do Índice Firjan de desenvolvimento municipal nos municípios do TCJ

\begin{tabular}{|c|c|c|c|c|c|c|}
\hline MUNICÍPIO & ANO & IFDM & $\begin{array}{c}\% \text { DE } \\
\text { MELHORIA } \\
\text { NO IFDM }\end{array}$ & $\begin{array}{c}\text { IFDM } \\
\text { EDUCAÇÃO }\end{array}$ & $\begin{array}{l}\text { IFDM } \\
\text { SAÚDE }\end{array}$ & $\begin{array}{c}\text { IFDM } \\
\text { EMPREGO E } \\
\text { RENDA }\end{array}$ \\
\hline \multirow{2}{*}{ Mateiros } & 2005 & 0,4259 & \multirow{2}{*}{$32,49 \%$} & 3686 & 0,5610 & 0,3480 \\
\hline & 2011 & 0,5643 & & 0,6363 & 0,3999 & 0,6567 \\
\hline \multirow{2}{*}{$\begin{array}{l}\text { Lagoa do } \\
\text { Tocantins }\end{array}$} & 2005 & 0,4494 & \multirow{2}{*}{$34,22 \%$} & 0,3178 & 0,5942 & 0,4362 \\
\hline & 2011 & 0,6032 & & 0,6368 & 0,7101 & 0,4627 \\
\hline \multirow{2}{*}{ Lizarda } & 2005 & $*$ & \multirow{2}{*}{$*$} & 0,3751 & 0,6508 & $*$ \\
\hline & 2011 & 0,4987 & & 0,5276 & 0,6893 & 0,2792 \\
\hline \multirow{2}{*}{$\begin{array}{c}\text { Novo } \\
\text { Acordo }\end{array}$} & 2005 & 0,4709 & \multirow{2}{*}{$37,56 \%$} & 0,4323 & 0,5289 & 0,4516 \\
\hline & 2011 & 0,6478 & & 0,6708 & 0,7865 & 0,4864 \\
\hline \multirow{2}{*}{ Rio Sono } & 2005 & 0,4172 & \multirow{2}{*}{$42,73 \%$} & 0,4824 & 0,5482 & 0,2210 \\
\hline & 2011 & 0,5955 & & 0,6671 & 0,7865 & 0,3449 \\
\hline \multirow{2}{*}{$\begin{array}{l}\text { Santa Tereza } \\
\text { do Tocantins }\end{array}$} & 2005 & $*$ & \multirow{2}{*}{ * } & 0,5415 & 0,6771 & $*$ \\
\hline & 2011 & 0,6258 & & 0,6908 & 0,8006 & 0,3859 \\
\hline \multirow{2}{*}{$\begin{array}{c}\text { São Félix do } \\
\text { Tocantins }\end{array}$} & 2005 & $*$ & \multirow{2}{*}{ * } & 0,3806 & 0,4642 & $*$ \\
\hline & 2011 & 0,4313 & & 0,6474 & 0,2618 & 0,3848 \\
\hline \multirow{2}{*}{$\begin{array}{c}\text { Ponte Alta do } \\
\text { Tocantins }\end{array}$} & 2005 & 0,5108 & \multirow{2}{*}{$5,66 \%$} & 0,4808 & 0,6514 & 0,4001 \\
\hline & 2011 & 0,5397 & & 0,6712 & 0,6354 & 0,3126 \\
\hline
\end{tabular}

Fonte: Elaboração própria, com base no Índice FIRJAN de desenvolvimento municipal.

De forma geral, os IFDM dos municípios do território do Jalapão, em 2011, estão abaixo da média Nacional, de 0,7320 pontos (IFDM, 2011), porém, comparando os resultados de 2005 e 2011 o quadro revela avanços significativos.

No IFDM consolidado, o município Rio Sono foi o que apresentou maior avanço com crescimento de $42,73 \%$. Considerando os crescimento de 48,70\%. No indicador emprego e renda, o município de Mateiros, atualmente referência na produção do artesanato do capim dourado, esboçou o crescimento de mais $88 \%$. O Quadro 2 aponta, também, para a retração em alguns indicadores como saúde em Mateiros, Ponte Alta do Tocantins, São Félix do Tocantins e emprego e renda em Ponte Alta do Tocantins, 
mas as evidências de impactos positivos são fortes e mostram que houve transformação socioeconômica que, de certo modo, foram motivadas pela projeção do turismo e do artesanato de capim dourado na região.

É certo que nem toda a evolução alusiva ao índice é decorrente exclusivamente das ações que o trabalho faz referência, programas governamentais sejam eles municipais, estadual ou federal, o desempenho do setor privado relacionado a outras atividades também geram efeitos em todo o território, mas a contribuição turística e do artesanato com o capim dourado, aos olhos dos próprios moradores, foram determinantes para esse progresso.

\section{Considerações Finais}

As mulheres da região do Jalapão desempenham os papéis reprodutivo, produtivo e comunitário de uma forma tão instintiva que fazem a definição de Moser (1993), de women's triple role ou 'o triplo papel das mulheres' ser identificada facilmente na realidade, evidenciando a valor das mulheres no desenvolvimento do TCJ.

As mulheres desse território, mesmo que de forma inconsciente, buscam no momento presente, criar novas oportunidades e formas de trabalho socialmente reinventadas e autossustentáveis. Fazendo uso de novas técnicas de trabalho, elas ampliam suas capacidades e tornam-se condutoras de suas histórias. Partindo da colocação Siliprandi e Cintrão (2011), é possível dizer que as mulheres dessa região contribuem para quebra de um círculo vicioso que vincula a figura da mulher exclusivamente ao ambiente doméstico e que torna invisível sua contribuição para o desenvolvimento que perpetua uma condição de "não direitos", de "não cidadania" e de desigualdade social.

Embora nem todos os trabalhos aqui reunidos expressem, de forma explícita, o papel das mulheres rurais no desenvolvimento do Jalapão, é possível concluir que muito mais que contribuir para a dinamização da economia e desenvolvimento da região as atitudes das mulheres jalapoeiras, em primeiro momento, e de toda a comunidade demonstram um despertar cidadão da comunidade em busca da transformação social através do potencial local existente.

No entanto, é notória a necessidade de se alcançar respostas mais concretas e claras sobre essa realidade, entender especificamente a realidade de cada município, ou abarcar outras vertentes que para além do turismo, do artesanato, e da agricultura também contribuam para $o$ desenvolvimento da região e que tenham participação ativa das mulheres.

1 Este texto foi produzido no âmbito dos Núcleos de Extensão em Desenvolvimento Territorial - NEDETs, com o apoio das seguintes entidades: Conselho Nacional de Desenvolvimento Científico e Tecnológico - CNPq, Ministério do Desenvolvimento Agrário - MDA, por intermédio da Secretaria do Desenvolvimento Territorial - SDT e da Diretoria de Políticas para Mulheres Rurais DPMR/SECEX/MDA, e a Secretaria de Políticas para Mulheres da Presidência da República - SPM/PR.

2 http://www.territoriosdacidadania.gov.br/dotlrn /clubs/territriosrurais/one-communityo

3 O Índice de Desenvolvimento Humano Municipal (IDHM) é uma medida composta de indicadores que mede o nível de desenvolvimento humano de determinada região por intermédio de indicadores que determinam uma vida longa e saudável (longevidade), acesso ao conhecimento (educação) e pelo padrão de vida (renda mensal per capita).

4 O coeficiente de Gini é um cálculo usado para medir a desigualdade social, desenvolvido pelo estatístico italiano Corrado Gini, em 1912. Apresenta dados entre o número 0 e o número 1 , onde zero 
corresponde a uma completa igualdade na renda (onde todos detêm a mesma renda per capta) e um que corresponde a uma completa desigualdade entre as rendas (onde um indivíduo, ou uma pequena parcela de uma população, detém toda a renda e os demais nada têm).

\begin{abstract}
5 Ação de Apoio a Projetos de Infraestrutura e Serviços em Territórios Rurais (PROINF), operacionalizada pela Secretaria de Desenvolvimento Territorial (SDT) Ministério do Desenvolvimento Agrário (MDA), tem com objetivo contribuir para a qualificação de processos produtivos e econômicos da agricultura familiar nos Territórios Rurais (MDA, 2015).
\end{abstract}

6 Guilhermina Rodrigues Matos (Dona Miúda) morreu com 82 anos, em 11 de novembro de 2010, foi considerada uma das 21 mulheres da História do Tocantins, em 2009, e coroada rainha do capim dourado em festa da colheita no mês de setembro de 2010, dois meses antes de morrer (MEDINA, 2102).

7 O Instituto Natureza do Tocantins (NATURATINS) é o órgão que executa a política estadual de meio ambiente do governo do Tocantins. Ele está vinculado atualmente à Secretaria Estadual de Meio Ambiente e Desenvolvimento Sustentável (SEMADES).

8 O Índice de Qualidade de Vida Humana IQV aborda aspectos materiais, culturais e sociais que influem na qualidade de vida mensurada por meio dos resultados das condições de moradia, aspectos sanitários, bens de consumo duráveis, acesso aos meios de comunicação e lazer, saúde, educação e emprego e renda.

\section{Referências}

ABRAMO, Laís. Igualdade de gênero e raça no trabalho: avanços e desafios / Organização Internacional do Trabalho. Brasília: OIT, 2010.

ALVES, Branca Moreira; PITANGUY, Jacqueline. O que é feminismo. São Paulo: Brasiliense, 1985.

BEAUVOIR, Simone. O segundo sexo. São Paulo: Nova Fronteira, 2014 [1949].
BELAS, Carla Arouca. Indicações Geográficas e a salvaguarda do Patrimônio Cultural: artesanato de Capim Dourado Jalapão - Brasil. 2012. Tese (Doutorado em Ciências Sociais em Desenvolvimento, Agricultura e Sociedade) Universidade Federal Rural do Rio de Janeiro, Rio de Janeiro.

BENVINDO, Rosângela Araujo Fernandes. Análise comparativa dos instrumentos de regulamentação das políticas de proteção ambiental e de promoção do ecoturismo: $\mathrm{O}$ Caso do P arque Estadual do Jalapão - TO. 2009. Dissertação (Doutorado em Arquitetura e Urbanismo) - Universidade de Brasília, Brasília.

BOURDIEU, Pierre. A dominação masculina. Rio de Janeiro: Bertrand Brasil, 2010 .

BRASIL. Territórios da cidadania: integração de políticas públicas para reduzir desigualdades. Março de 2009. Disponível em: http://www.territoriosdacidadania.gov.br. Acesso: 01 de jun. de 2015.

CALÁS, Marta; SMIRCICH, Linda. From 'The woman's' point of view: feminist approaches to organizations studies. In: CLEGG, Stewart (et al). Handbook of organization studies. London: Sage, 1996, p. $284-346$.

CATÁlogo CAPIM DOURADO. Design popular do Jalapão. Manejo comunitário sustentável. Disponível em: Acesso em: 22 maio. 2014.

DALLABRIDDA, Valdir Roque. Desenvolvimento regional: porque algumas regiões se desenvolvem e outras não?. Santa Cruz do Sul 1 ed: EDUNISC. 2010 . 
FIRJAN. Índice FIRJAN de Desenvolvimento Municipal (IFDM). Disponível em: $<$ http://www.firjan.org.br/ifdm/>. Acesso em 20 março 2015.

FRIEDAN, Betty. Mística feminina. Petrópolis: Vozes, 1971.

Historical Review, v. 91, n. 5, p. 1053 1075, 1986.

HORA, Karla; BUTTO, Andrea. Políticas públicas para mulheres rurais no contexto dos territórios da cidadania. In: BUTTO, Andrea (et al) Mulheres rurais e autonomia: formação e articulação para efetivar políticas públicas nos Territórios da Cidadania. Brasília: Ministério do Desenvolvimento Agrário, 2014, p. 14 - 45.

JENAINATI, Cathia; GROVES, Judy. Introducing Feminism. Malta: Gutenberg Press, 2007.

MANZINI, Eduardo José. Entrevista semiestruturada: análise de objetivos e de roteiros. IN: Seminário internacional de pesquisa e estudos qualitativos, 2,2004. Bauru. A pesquisa qualitativa em debate. Anais. USC, 2004.

MEDINA, Maria de Fátima Rocha. Dona miúda heranças que o brilho não ofusca. Disponível em: $\quad<$ http://ulbrato.br/encena/2012/11/08/Dona-Miudaherancas-que-o-brilho-nao-ofusca $>$. Acesso em 13 de março de 2015.

MELLO, Janaina. A cultura Xerente e seu artesanato dourado. Patrimônio, memória e registro na região do Jalapão - Tocantins. Patrimônio e Memória, v. 10, n. 2, p. 75 90, 2014.

MILL, Stuart. A sujeição das mulheres. São
Paulo: Escala, 2006 [1869].

MOSER, Caroline. Gender planning and development Theory, practice and training. New York: Routledge, 1993.

NARCISO, Vanda; HENRIQUES, Pedro Damião de Sousa. O Papel das Mulheres no Desenvolvimento Rural: Uma Leitura para Timor-Leste. CEFAGE-UE Working Paper, 2008/04, p. $1-18$.

NUNES, Lília Tereza Diniz. Design e cultura: um olhar sobre o artesanato de Capim Dourado. 2013. Dissertação (Mestrado em Design) - Universidade Anhembi Morumbi, São Paulo.

ORTEGA, Antonio Cesar. Territórios deprimidos: desafios para as políticas de desenvolvimento rural. Campinas, SP: Alínea; Uberlândia, MG: Edufu, 2008.

PEREIRA, Ana Lucia. Famílias Quilombolas: história, resistência e luta contra a vulnerabilidade social, insegurança alimentar e nutricional na Comunidade Mumbuca - Estado do Tocantins. 2012. Tese (Doutorado em Sociologia) - Universidade Estadual Paulista, Araraquara, São Paulo.

SALES, Celecina de Maria Veras. Mulheres rurais: tecendo novas relações e reconhecendo direito. Estudos Feministas, v. 15, n. 2 , p. $437-443,2007$.

SAMPAIO, Maurício Bonesso (et al). Boas práticas de manejo para o extrativismo sustentável do capim dourado e buriti. Brasília: Embrapa Recursos Genéticos e Biotecnologia, 2010.

SANTOS, Eliene Gomes dos (et al). Perspectivas de sustentabilidade e 
potencial de desenvolvimento local: a comunidade de Mumbuca e o estabelecimento do turismo na região do Jalapão. Encontro Latino-Americano sobre edificações e comunidades Sustentáveis, 2, 2007, Campo Grande, MS.

SANTOS, Flávia Rodrigues dos. A relação entre o desenvolvimento do turismo e a percepção ambiental das mulheres que vivem no entorno do Parque Estadual do Jalapão, TO. Anais do VII Seminário Fazendo Gênero 28, 29 e 30 de 2006, Gênero, Etno-conhecimento e Meio Ambiente ST. 31.

SANTOS, Flávia Rodrigues dos. As Pessoas e a conservação do Cerrado: o caso do Parque Estadual do Jalapão. 2007. Dissertação (Mestrado, Programa de PósGraduação em Ciências do Ambiente) Universidade Federal do Tocantins, Palmas.

SAPIEZINSKAS, Aline. Como se constrói um artesão - negociações de significado e uma "cara nova" para as "coisas da vovó". Horizontes Antropológicos, v. 18, n. 38, p. $133-158,2012$.

SCOTT, Joan. Gender: a useful category of historical analysis. The American

SILIPRANDI, Emma; CINTRÃO, Rosângela. As mulheres agricultoras no Programa de Aquisição de Alimentos (PAA). Segurança Alimentar e Nutricional, v. 18, n. 2, p. $12-32,2011$.

SOUSA, Aline Tavares De; PARENTE, Temis Gomes. A Atividade Artesanal do Capim Dourado na Região do JalapãoTO: Uma nova perspectiva para o empoderamento das mulheres. 2012. (Apresentação de Trabalho/Outra). sustentável.
$<$ http://www.centraldocerrado.org.br/blog/wp content/uploads/2009/03/catalogo-capimdourado.pdf $>$. Acesso em 22 de Maio de 2015.
Recebido em 28 de setembro de 2015. Aceito em 15 de dezembro de 2015. 